\title{
TRADUÇÃO: A IDEOLOGIA DO TRIBALISMO (THE IDEOLOGY OF TRIBALISM, DE ARCHIE MAFEJE')
}

\author{
Anderson Bastos Martins
}

\begin{abstract}
Resumo: Este artigo, de autoria do antropólogo sul-africano Archie Mafeje, foi publicado pela primeira vez em 1971 e está sendo traduzido no Brasil pela primeira vez. No artigo, Mafeje analisa o uso dos conceitos de "tribo" e "tribalismo" nas ciências sociais e na antropologia por estudiosos que pesquisam o continente africano. O objetivo de Mafeje é demonstrar que, nesse contexto, os dois termos têm por base uma abordagem ideológica de extração europeia e seu uso continuado no século XX representa um anacronismo conceitual. A tradução é de Anderson Bastos Martins (Universidade Federal de Juiz de Fora).
\end{abstract}

\begin{abstract}
This article, written by South African anthropologist Archie Mafeje, was first published in 1971 and appears for the first time in translation in Brazil. In the article, Mafeje analyses the use of the concepts of "tribe" and "tribalism" in the social sciences and in anthropology by scholars who investigate the African continent. Mafeje's aim is to demonstrate that, in such a context, both terms are grounded in an ideological approach with European sources and that their continued usage in the twentieth century represents a conceptual anachronism. The translation is signed by Anderson Bastos Martins (Universidade Federal de Juiz de Fora).
\end{abstract}

\section{Introdução}

Poucos autores foram capazes de escrever sobre a África sem fazer referências constantes ao "tribalismo". Seria esta a marca que distingue o continente? Ou será mero reflexo do sistema de percepções daqueles que escrevem sobre a África e de seus "convertidos" africanos? É muito difícil desembaraçar a realidade objetiva da percepção subjetiva, quase tão espinhoso quanto purificar os conceitos das ciências sociais de todas as conotações ideológicas. Não poderia a história africana, escrita não por europeus, mas pelos próprios africanos, ter empregado conceitos diferentes e

\footnotetext{
${ }^{1}$ Archibald Boyce Monwabisi (Archie) - Mafeje nasceu em 30 de março de 1936, em Gubenxa, na região que hoje é o Transkei, na África do Sul. Pertence à primeira geração de acadêmicos africanos do pósindependência do continente. Como Professor de Antropologia e de Sociologia teve passagem por Universidades da Tanzânia, Holanda, Egito, Zimbabwe, Namíbia, dentre outras. Faleceu em Pretória, em 28 de março de 2007, antes do seu aniversário de 71 anos.
} 
narrado uma história diferente? E se tivesse sido esse o caso, qual teria sido a explicação teórica? As coisas são aquilo de que são chamadas, ou possuem uma existência independente da nomenclatura que se fixa a elas? Quando se trata da África, as respostas variam independentemente de ser o observador um idealista liberal, um materialista marxista, ou um "convertido" africano.

Defende-se normalmente a tese de que o comportamento social na África é tão diverso, tão instável, tão fluido que é praticamente impossível classificá-lo ou tratá-lo com qualquer grau de estabilidade. Eu me sinto inclinado a pensar que o problema da África não é o comportamento empiricamente diversificado, mas principalmente a ideologia, e especificamente a ideologia do "tribalismo". O colonialismo europeu, como todas as épocas históricas, trouxe consigo certos modos de reconstruir a realidade africana. Ele via as sociedades africanas como particularmente tribais. Esse método produziu alguns pontos cegos ou predisposições ideológicas que dificultaram, para aqueles associados com o sistema, enxergar essas sociedades sob qualquer outra ótica. Por essa razão, persistiram certos modos de pensar entre os pesquisadores europeus na África e seus congêneres africanos, a despeito das várias mudanças políticas e econômicas importantes que ocorreram no continente nos últimos setenta e cinco a cem anos. $^{2}$ Portanto, se o tribalismo é entendido como uma peculiaridade africana, então a ideologia em si tem origem particularmente europeia.

\section{Desvios antropológicos}

Numa publicação recente, Philip Hugh Gulliver, talvez sentindo-se um pouco culpado pelo uso permanente do termo "tribo", explica:

Nós não continuamos a usá-lo em qualquer espírito de antagonismo, menos ainda de insulto ou depreciação. Nós o usamos simplesmente porque ele continua a ser amplamente usado na porção leste da África quando se fala inglês [...] lá [...] entre os cidadãos (GULLIVER, 1969, p. 2).

\footnotetext{
${ }^{2}$ Este artigo foi publicado em 1971 e nenhum número ou data mencionado no original foi alterado para se ajustar à data da tradução. (N. T.).
} 
A justificativa é repetida em ao menos três outros momentos, mas levanta diversas questões. As coisas são necessariamente aquilo de que são chamadas? Em segundo lugar, até que ponto os cientistas sociais devem se ater à terminologia dos nativos? E, por outra, não é significativo que o termo ocorra justamente quando se fala inglês? A população indígena da África do Sul não possui uma palavra para dizer "tribo", mas apenas para "nação", "clã" e "linhagem". Tradicionalmente, as pessoas são identificadas por território "Você vem da terra de quem (de qual Chefe)"?

Em diversas circunstâncias, as autoridades coloniais ajudaram a criar as coisas chamadas "tribos" no sentido de comunidades políticas, processo esse que coincidiu com e foi auxiliado pela preocupação dos antropólogos com as "tribos" e que ofereceu o material, bem como a base ideológica, daquilo que hoje chamamos de "tribalismo". Deve surpreender, portanto, que o africano moderno, que é um produto do colonialismo, lance mão da mesma linguagem? Se esse é um grande enigma para o cientista social moderno, não o era para Marx, que em 1845 escreveu:

Os pensamentos da classe dominante são também, em todas as épocas, os pensamentos dominantes; em outras palavras, a classe que é o poder material dominante numa determinada sociedade é também o poder espiritual dominante. A classe que dispõe dos meios da produção material dispõe também dos meios da produção intelectual, de tal modo que o pensamento daqueles aos quais são negados os meios de produção intelectual está submetido também à classe dominante (MARX; ENGELS, 1998, p. 42)3.

Os antropólogos e cientistas sociais anglo-saxões, mencionam, à sua usual maneira sutil, os "precursores" ou os "grupos de referência".

Por algum tempo, e a despeito das mudanças que vinham ocorrendo, a maior parte dos antropólogos britânicos manteve o interesse no estudo de tribos "puras", ignorando todas as inovações dessas sociedades no decorrer do século XX. Quando muito, trataram tais inovações como invasões, ao mesmo tempo indesejáveis e periféricas em relação à vida real das pessoas. Isso veio

${ }^{3}$ Optei por citar a tradução brasileira publicada pela primeira vez em 1989 pela editora Martins Fontes. 
ao encontro das teorias do domínio indireto defendidas por Lord Lugard e Sir Donald Cameron. Como sabemos hoje, o domínio indireto trouxe consequências políticas e econômicas muito diretas. As sociedades africanas estavam sendo atraídas para o interior de um complexo de relações políticas e econômicas extrativistas, cujos impactos não podiam ser ignorados mesmo que pelo antropólogo mais fixado nas "tribos". Na realidade, as convicções liberais da maioria dos antropólogos foram acionadas e eles começaram a lamentar a "desintegração" subsequente das sociedades tradicionais africanas, a perda do "equilíbrio e coesão" originais. Eles enxergaram com horror e alguma apreensão a "degradação da ética africana”.

\section{A mudança de perspectiva}

Esse foi o ponto de inflexão para a maioria dos antropólogos; a situação não era tão estática quanto eles supunham. A partir de 1945, alguns antropólogos, como o casal Monica e Godfrey Wilson, Raymond Firth, Robert Redfield e Audrey Richards começaram a falar em "mudança social". ${ }^{4}$ Em 1959, Max Gluckman ainda podia se sentir à vontade para dizer que "a tradição da antropologia ainda é 'tribalista' e daí a tendência em fazer da tribo e do homem tribal o ponto de partida da análise" (GLUCKMAN, 1961, p. 69). Entretanto, como podemos ver em seus trabalhos posteriores, o próprio Gluckman jamais abandonou essa tradição. ${ }^{5}$

Nesse intervalo, a base da discussão sobre o que viríamos a nomear com os termos "tribo" ou "tribalismo" havia sido dada em 1956, quando James Clyde Mitchell publicou um estudo considerado hoje um clássico entre os antropólogos sobre a dança Kalela. De acordo com a terminologia popular,

\footnotetext{
${ }^{4}$ Cf. G. e M. Wilson com The analysis of social change (Cambridge University Press, 1945); R. Firth com Elements of social organization (Watts, 1951); R. Redfield com The primitive world and its transformation (Cornell University Press, 1953); A. I. Richards com Economic development and tribal change (W. Heffer \& Sons Ltd., 1954).

${ }^{5}$ Cf. GLUCKMAN com Order and rebellion in tribal Africa (Cohen \& West, 1963) e suas contribuições em outras publicações, como "The tribal areas in South and Central Africa", publicado em KUPER, L.; SMITH M. G. (Org.). Pluralism in Africa (University of California Press, 1969); "Tribalism, ruralism and urbanism in plural societies", publicado em TURNER, V. W. (Org.). Colonialism in Africa, 1870-1960, v. 3, Profiles of change (Cambridge University Press, 1971) e "Interhierarchical roles: professional and party ethnics in the tribal areas in South and Central Africa, publicado em SWARTZ, M. (Org.). Local-Level politics (Aldine, 1968).
} 
tratava-se de uma dança tribal praticada na região conhecida como o Cinturão do Cobre na África Central. Demonstrando coragem, Mitchell chegou às assombrosas conclusões de que, longe de ser uma expressão de tribalismo, a dança Kalela era uma expressão de diferenciação social e de graus de prestígio na cidade, e que, nesta, ao contrário das áreas rurais, o “tribalismo" era apenas uma "categoria de interação" (MITCHELL, 1956). Essa revelação teve efeito significativo sobre os antropólogos, e poucos seriam os que, a partir daí, realizariam um estudo urbano sem repetir a nova fórmula: "o tribalismo urbano é diferente do rural". Essa continua a ser a fórmula antropológica padrão, como se vê nos editoriais de Philip Hugh Gulliver e em alguns dos artigos publicados no livro por ele organizado e intitulado Tradition and transition in East Africa (Tradição e transição na África Oriental) de 1969. Arnold Leonard Epstein (1958) foi um dos muito poucos autores que ousaram sugerir que os africanos de áreas urbanas realmente poderiam rejeitar o "tribalismo" como sendo irrelevante aos seus problemas. Ele descobriu que os operários das minas de cobre de Luanshya se recusavam a aceitar os "concelhos de anciãos" como seus representantes ou líderes nas disputas com a administração das minas. Ao mesmo tempo, os trabalhadores sem contrato entre eles suspeitavam dos líderes escolhidos entre o pessoal com contrato, que geralmente agiam em benefício de seu próprio grupo. Esse foi mais um momento de formação de classes entre os africanos.

Quaisquer que sejam os detalhes e as inibições, a análise da mudança social possibilitou aos antropólogos observar a transformação das sociedades tribais com um viés menos negativo. Os "ventos da mudança" lograram ser aceitos como um fato, e a "independência", com tudo o que ela traz consigo, estava se tornando rapidamente uma realidade e não mais uma ideia vaga num futuro distante. Isso chamou a atenção dos cientistas políticos, que começaram a aderir, um após o outro. ${ }^{6}$ Tendo aceitado a ideia de estados-nação modernos, eles trouxeram consigo um novo credo - a

${ }^{6}$ Liderados por David Apter. Cf. seus livros The gold coast in transition (Princeton University Press, 1955) e The political kingdom of Uganda (Princeton University Press, 1961). V. também James S. Coleman com Nigeria: background to nationalism (University of California Press, 1958) e K. W. J. Post com The Nigerian federal elections of 1959: politics and administration in a developing political system (Oxford University Press, 1963) 
"modernização". Na euforia da "independência" e sob o fervor desse novo credo, qual viria a ser a atitude dos antropólogos? Estando há mais tempo no campo de investigações, eles tinham razão de se preocupar e seguiram fiéis às suas "tribos". Mas dessa vez eles agiram no sentido de estabelecer uma nova verdade, a saber, a "persistência e a resiliência" dos sistemas tribais ao invés de sua “desintegração” ou de seu “desequilíbrio". ${ }^{7}$

Já não faltavam avisos, como, por exemplo, no título escolhido por William Watson para seu livro Tribal cohesion in a money economy (Coesão tribal numa economia monetária) publicado em 1958. Esse tem sido o tema na maior parte da última década. Trata-se de uma meia-volta interessante entre os antropólogos e representa um deslocamento (não uma mudança) na perspectiva ideológica deles. Como se pode perceber em sua admiração por tribos pioneiras, como os Baganda, os Kikuyu e os Ibo, os antropólogos aderem ao credo da "modernização". No entanto, ao contrário dos cientistas políticos e dos nacionalistas africanos, eles não a enxergam como necessariamente incompatível com o "tribalismo" e o "tradicionalismo". Mesmo assim, um antropólogo irá trair-se se oferecer "valores e instituições tribais" como explicação para o fracasso dos africanos em adotar a modernidade. Nesse ponto, o antropólogo demonstra ser um incrementalista contraditório e não pode dizer que não o é, porque sua concepção orgânica de estrutura social e de instituições o compromete de maneira irrefutável.

Enquanto antropólogos usam sua ideologia tribal para explicar tanto os sucessos quanto os fracassos da modernização, cientistas políticos de todos os matizes utilizam a sua apenas para explicar os fracassos. Por essa razão, eles falam de forma mais consistente e conveniente do que os antropólogos sobre os problemas de "integração", "penetração" e "mobilização". Entretanto, em termos conceituais, eles enfrentam maiores problemas do que os antropólogos. Em primeiro lugar, a despeito de sua linguagem "tribal", eles sabem muito menos sobre as tribos do que os antropólogos. Em segundo lugar, essa mesma linguagem "tribal" torna-lhes difícil oferecer uma explicação de fenômenos semelhantes em outros lugares

7 Cf. I. Lewis no verbete dobre "tribalismo" na International Encyclopedia of Social Sciences (Macmillan, 1968, v. XVI, p. 146-150. 
do mundo sem se tornarem presas fáceis da ideologia etnocêntrica mencionada na introdução deste artigo. Os antropólogos podem facilmente escapar de um destino semelhante, porque sua preocupação profissional sempre foi o estudo de "tribos" ou de "sociedades primitivas". Naturalmente, nem mesmo isso é mais verdade hoje em dia.

\section{O problema conceitual recolocado}

Até aqui eu apenas apresentei e ilustrei o meu problema, mas ainda não o comprovei. A questão básica real é se é possível haver "tribalismo" sem tribos. Mas como testar para averiguar a existência de tribos? A antropologia clássica definiu as tribos como "comunidades autônomas e autossuficientes que praticam economia de subsistência com nenhum ou quase nenhum comércio externo". Mas em 1940, Meyer Fortes e Edward Evan EvansPritchard apresentaram a distinção entre "estados centralizados" e sociedades "sem estado" ou "acéfalas" (FORTES; EVANS-PRITCHARD, 1940). Desde então, os antropólogos enfrentam dificuldades ao tentar decidir se todas as formas africanas de governo eram tribos ou se algumas delas se credenciavam para o epíteto mais respeitável de "estado". Questões de escala parecem relevantes, mas os antropólogos se deram por satisfeitos ao se referirem a unidades multitribais maiores, como o Reino Luapula de Kazembe na África Central, o Império Zulu de Tshaka na África do Sul e a Confederação Ashante na África Ocidental, como "supertribos". Em 1956, Isaac Shapera encarregou-se de desfazer parte da confusão e de revisar a posição dos antropólogos. Ele definiu as tribos como “comunidades políticas' separadas, cada uma reivindicando direitos exclusivos sobre determinado território e gerindo seus assuntos internos independentemente de um controle externo" (SCHAPERA, 1956, p. 203).

Ao final, territorialidade, governo primitivo exercido pelos chefes e anciãos e economia primitiva de subsistência emergem como as características primárias que distinguem a tribo de outras formas de organização humana. A "cultura” jamais foi incluída na lista até a chegada da cruzada da "modernização" no trabalho de cientistas políticos e sociólogos 
pluralistas como Michael Garfield Smith e James Clyde Mitchell. ${ }^{8}$ É, portanto, muito instrutivo observar que, em 1969, Gulliver define tribo como "todo grupo de pessoas diferenciado, seja por seus membros ou por elementos externos, com base em critérios culturais regionais" (GULLIVER, 1969, p. 24). Vemos, assim, que agora a "tribo" passa a ser questão de percepção subjetiva, como se disséssemos: “É dessa forma que os nativos a veem e a descrevem”.

Embora suas motivações sejam suspeitas, os antropólogos podem ter tido razão quando insistiram que as sociedades tradicionais ou précoloniais africanas, pequenas ou grandes, eram tribos. Se tivéssemos circunscrito o termo "tribo" a formas específicas de organização econômica, política e social que podem ser fixadas no espaço e no tempo, como é minha intenção, não estaríamos emaranhados em tamanha confusão e tal teor de inconsistências. Uma sociedade relativamente indiferenciada, praticando uma economia primitiva de subsistência e gozando de autonomia local, pode legitimamente ser designada como "tribo". Quando tal sociedade se empenha em manter sua estrutura básica e autonomia local, mesmo em condições econômicas e políticas alteradas, é talvez possível dizer que ela está demonstrando "tribalismo". Mas impor o mesmo conceito a sociedades que foram efetivamente penetradas pelo colonialismo europeu e atraídas para dentro de uma economia monetária capitalista e um mercado mundial representa uma séria transgressão. A nova divisão de trabalho, os novos modos de produção e o sistema de distribuição de bens materiais e de poder político dão às sociedades africanas modernas uma base material e social fundamentalmente diferente. ${ }^{9}$ Está claro, portanto, que não é uma questão de escala, mas uma questão de aspectos qualitativos da organização social e econômica.

Isso não equivale a negar a existência de ideologias e afinidades tribais na África. Meu argumento é o de que estas precisam ser compreendidas - e conceituadas - diferentemente nas circunstâncias atuais. Existe uma real diferença entre o homem que, em nome de sua tribo, busca manter sua integridade e autonomia tradicionais e aquele que lança mão da

8 Cf. M. G. Smith em Government in Zazzau (Oxford University Press, 1960) e J. C. Mitchell com Tribalism and the plural society (Oxford University Press, 1960).

${ }^{9}$ Cf. MARX K.; ENGELS F., A ideologia alemã. 
ideologia tribal a fim de sustentar uma posição de poder, não na região tribal, mas, antes, na capital moderna, sendo seu objetivo maior enfraquecer e explorar os supostos homens tribais. O fato de que isso funciona, como é frequentemente relatado pelos próprios apologistas das tribos, não é prova de que existam "tribos" ou "tribalismo" em qualquer sentido objetivo. Quando muito, é uma demonstração de falsa consciência da parte dos supostos homens tribais, que sancionam uma ideologia incoerente com sua base material e, dessa forma, atendem, sem o saber, à demanda pela exploração deles mesmos. Da parte da nova elite africana, estamos diante de um disfarce ou uma distorção que ela emprega para escamotear seu papel exploratório. Trata-se de uma ideologia no sentido marxista original e essa elite a compartilha com seus companheiros apologistas europeus.

\section{O impasse teórico}

Para além de sua ideologia específica - que foi habilmente colocada em evidência por John Argyle (1971) num estudo recente - os antropólogos, sociólogos e cientistas políticos parecem sofrer de uma incapacidade comum para distinguir de maneira suficiente e consistente entre teoria social e ação social. Ainda que seja correto dizer que existe uma relação entre classificação social e comportamento social, isso não significa que ambos sempre coincidem. Analisadas sociologicamente, as coisas não são necessariamente aquilo de que são chamadas socialmente. A frequente afirmação feita pelos antropólogos que estudam sociedades urbanas de que "o tribalismo urbano é diferente do tribalismo rural" é um exemplo de como o mesmo termo classificatório é utilizado por cientistas e atores sociais para descrever fenômenos completamente diferentes. Claude Lévi-Strauss (1963) sugeriu que os modelos conscientes são mais pobres que os inconscientes, porque têm menos a nos dizer sobre a realidade objetiva. É claro que, sendo ele próprio membro do clube, Lévi-Strauss não iria aplicar a mesma observação a seus colegas cientistas sociais.

É importante observar que sistemas classificatórios são menos definidos no espaço do que sistemas de ação. É por isso que vem se tornando cada vez mais difícil para os antropólogos insistir na territorialidade como 
sendo a base do "tribalismo". De acordo com suas próprias observações, o "tribalismo" agora se expandiu até mesmo para as cidades. Sob as condições atuais, os chamados "homens tribais" não vivem na mesma área, embora talvez ainda se identifiquem uns com os outros em contextos específicos. Além disso, mesmo nas áreas rurais, a residência em regiões que são conhecidas por nomes tribais não está restrita a nenhuma “tribo" particular, mas, mesmo assim, os habitantes talvez ainda se identifiquem intensamente com a região. Certamente era esse o caso no Transkei, África do sul, onde desenvolvi meu trabalho de campo em 1963. A mesma tendência foi observada entre os migrantes da Cidade do Cabo. ${ }^{10}$ Sob as condições atuais, isso destacaria a importância do regionalismo em detrimento do tribalismo.

A questão da identidade cultural está associada de perto ao que dissemos acima. Antes já havíamos observado que a "cultura" não foi um dos critérios utilizados pelos antropólogos britânicos para definir a "tribo". Isso se deve a uma de duas razões: ou eles eram estruturalistas intransigentes ou perceberam que as fronteiras culturais eram mais difusas do que as políticas. Na África do Sul, pode-se dizer que os falantes de xhosa compartilham uma cultura comum numa área muito extensa, mas foram divididos entre diversas unidades políticas autônomas. Assim como as "tribos" fictícias que foram mencionadas antes neste artigo, eles poderiam usar esse elo cultural a fim de conquistar um lugar mais confortável na sociedade sul-africana moderna e industrial. Será que isso constituiria "tribalismo"? Um antropólogo padrão, assim como os nativos afetados desfavoravelmente por um posicionamento como esse, iria acusá-los de "tribalismo". Mas o senso de pertencimento xhosa no sentido cultural, a despeito de seu impacto facilitador, seria representativo de algo completamente diferente. Essa afirmação já foi feita por diversos autores, embora a maioria deles não tenha sido capaz de superar suas predisposições ideológicas. Alguns exemplos são suficientes à guisa de demonstração:

Lealdades e identificações tribais estão associadas de perto aos apelos [...] a uma cultura tradicional mesmo onde a base concreta do tribalismo, seja para conflitos

${ }^{10}$ Cf. WILSON; MAFEJE, 1963, p. 47-49. 
intertribais ou alegações de participação desfavorável, está firmemente estabelecida na competição contemporânea por poder e vantagens culturais (GULLIVER, 1969, p. 12).

O que é básico aqui não é a "rivalidade tribal", mas um sistema em que a competição é de importância fundamental e que fornece uma infinidade de fontes nas quais os competidores podem se apoiar (GRILLER, 1969, p. 320).

Isso nos leva ao segundo sentido de tribo, a saber, um conceito usado por citadinos para descrever divisões urbanas e para distribuir a culpa. Nessa função, é um conceito frequentemente emocional e mítico e, portanto, altamente flexível, permitindo que várias pessoas tenham explicações diferentes para a mesma situação. (PARKIN, 1969, p. 295).

Ficamos com a sensação de que todos estão atados por uma corrente e não podem avançar. Raymond J. Apthorpe observou que analisada sociologicamente, a única coisa que é sempre anterior não é o fenômeno do tribalismo propriamente dito - seja este o que for - mas o aparato de conceitos e ideias com o qual os cientistas sociais e outros tentam compreendê-lo. (APTHORPE, 1968, p. 22).

Para escapar àquilo que Marx chamou de "baboseiras idealistas" (MARX; ENGELS, 1998, p. 36), Apthorpe poderia ter acrescentado que as condições para as quais os vários "tribalismos" constituíram uma resposta já existiam antes do fenômeno em si e eram, na realidade, fruto de uma privação relativa. $^{11}$

\section{Conclusão}

O principal objetivo de Apthorpe foi o de indagar se o tribalismo importa. A resposta é: se o tribalismo não importa, a ideologia do tribalismo, promovida tanto por teóricos expatriados quanto por apologistas africanos de classe média emergente, importa e muito. Primeiramente, ela hipersimplifica, mistifica e obscurece a natureza real das relações econômicas e de poder

\footnotetext{
11 Posso citar GULLIVER, 1969, p.24 ou ainda a pesquisa de um mestrando da Universidade de Makerere que afirmou que o "tribalismo" não começou em Kigeze antes de 1958.
} 
internas entre os africanos bem como aquelas existentes entre a África e o mundo capitalista, quase da mesma forma com que o termo "feudalismo", quando aplicado à América Latina, camufla o papel crucial desempenhado pelo capital financeiro internacional e pelo imperialismo na acentuação e perpetuação da formação social existente naquela parte do mundo. Em segundo lugar, ela estabelece uma distinção perversa e altamente suspeita entre os africanos e os demais povos do mundo. A condescendência contida em afirmar "chame-os pelo mesmo nome" tem maior potencial de produzir ressentimentos do que de facilitar a comunicação. E, por último, trata-se de um termo equivocado e anacrônico que impede uma análise intercultural.

Se o particularismo regional, facilitado pela existência de segmentos culturais dentro da sociedade como um todo, e a formação de classes fossem tratados como realidades, em lugar das ideologizações em torno de "tribos" e de "tribalismo", os insights já logrados a partir da experiência histórica europeia, asiática e americana renderiam frutos mais concretos em prol da transformação africana e ofereceriam melhores perspectivas para futuras análises das sociedades humanas em todo o mundo. Se quisermos ser capazes de contribuir para esse tipo de universalismo enquanto cientistas sociais, precisamos de conceitos generalizáveis com alta capacidade explanatória - e "tribalismo" certamente não é um deles.

\section{Referências}

APTHORPE, R. J. Does tribalism really matter? Transition, v. 37, out. 1968.

ARGYLE W. J. European nationalism and African tribalism. In: GULLIVER, P. H. (Org.) Tradition and transition in East Africa. Berkeley/Los Angeles: University of California Press, 1971. p. 41-57.

EPSTEIN, A. L. Politics in an urban African community. Manchester: Manchester University Press, 1958.

FORTES, M.; EVANS-PRITCHARD, E. E. (Org.). African political systems. Londres: Oxford University Press, 1940.

GLUCKMAN M. Anthropological problems arising from the African Industrial Revolution. In: SOUTHALL, A. W. (Org.). Social change in modern Africa. Londres: Oxford University Press, 1961, p. 69. 
TRADUÇẦ: A IDEOLOGIA DO TRIBALISMO (THE IDEOLOGY OF TRIBALISM, DE ARCHIE MAFEJE)

GRILLER, R. D. The tribal factor in an East African trade union. In: GULLIVER, P. H. (Org.). Tradition and transition in East Africa: studies of the tribal element in the modern era. Londres: Routledge/Keagan Paul, 1969.

GULLIVER, P. H. (Org.). Tradition and transition in East Africa: studies of the tribal element in the modern era. Londres: Routledge/Keagan Paul, 1969.

LÉVI-STRAUSS, C. Structural Anthropology. Nova York: Basic Books, 1963, p. 281-282.

MAFEJE, A. Leadership and change: a study of two South African peasant communities. Dissertação de Mestrado. Universidade da Cidade do Cabo, 1963.

MARX, K.; ENGELS, F. A ideologia alemã. Trad. Luis Cláudio de Castro e Costa. São Paulo: Martins Fontes, 1998.

MITCHELL, J. C. The Kalela dance. Lusaka, 1956, Rhodes-Livingstone Papers n. 27.

PARKIN, D. J. Tribe as fact and fiction in an East African City. GULLIVER, P. H. (Org.). Tradition and transition in East Africa: studies of the tribal element in the modern era. Londres: Routledge/Keagan Paul, 1969.

SCHAPERA I. Government and politics in tribal societies. Londres: Watts, 1956.

WILSON, M.; MAFEJE, A. Langa: a study of social groups in an African township. Londres: Oxford University Press, 1963. p. 47-49.

Recebido em 20 de novembro de 2020

Aceito em 15 de dezembro de 2020 